\title{
Professores de língua inglesa para crianças: interface entre formação inicial e continuada, experiência e fazer pedagógico
}

\author{
English language teachers for young learners: \\ interface between in-service education, \\ experience and teaching practice
}

Leandra Ines Seganfredo Santos*

Universidade do Estado de Mato Grosso

Sinop - Mato Grosso / Brasil

RESUMO: O foco deste estudo é discutir a formação inicial e continuada de docentes que atuam no ensino de Língua Estrangeira, em especial, no ensino de Língua Inglesa para crianças que frequentam anos iniciais do Ensino Fundamental, em contexto de escola pública. Os dados, provenientes de um grupo de cinco docentes, foram coletados mediante uso de questionários, entrevistas, sessōes reflexivas, logs, acompanhamento do fazer pedagógico e da participação na Formação Continuada e em eventos acadêmico-científicos. Os resultados mostram que a Formação Continuada, mediante cursos e participação em eventos, por exemplo, são muito importantes na vida profissional do docente, principalmente, quando proporcionam socialização de experiências do fazer pedagógico.

PALAVRAS-CHAVE: Língua Inglesa para crianças; formação docente; experiência.

ABSTRACT: This study focuses on the discussion concerning the second language teachers' education, especially those who teach English for young learners in first years of public elementary schools. The data were collected from a group of five teachers by using questionnaires, interviews, reflective sections and logs. The teachers were followed in their teaching practice in the schools where they work, and also in their participation in continued education and academic and scientific events. The results show that continuing teaching education through courses and participation in events, for instance, are very important in teachers' professional life, mainly when they allow them to share their teaching experiences.

KEYWORDS: English Language for Young Learners; Teaching staff education; Experience.

\footnotetext{
*leandraines@hotmail.com
} 


\section{Introdução}

O ensino de línguas que não a materna passou a ser visto como ação profissional apenas no último século. No Brasil, somente no início dos anos trinta a modernidade no ensino de línguas marcou seu ingresso no panorama dos países que se sobressaem na produção mundial do conhecimento organizado para o ensino-aprendizagem de outros idiomas (ALMEIDA FILHO, 2003). Por considerar a inexistência de oferta protocolar de formação docente de Língua Inglesa (LI) para atuação em anos iniciais ${ }^{1}$ do Ensino Fundamental (EF), este texto objetiva discutir a Formação Inicial (FI) e Formação Continuada (FC) de professores de LI e, mais especificamente, a atuação deste profissional no ensino para crianças que frequentam escolas públicas, com base nos dizeres e fazeres de um grupo de docentes.

Os dados coletados são provenientes de um estudo qualitativo ${ }^{2}$ desenvolvido na Rede Municipal de Ensino (REME) em uma cidade nortematogrossense (SANTOS, 2009). Para compor o quadro de participantes, cinco docentes de LI que atuam com crianças foram selecionadas. Elas são formadas em Letras, e quatro delas têm habilitação em Língua Portuguesa (LP) e LI e uma delas em LP e Língua Espanhola e apresentam em seus currículos, diferentes especializações. Quatro das professoras atuam no ensino de LI em anos iniciais, e uma atua até o nono ano do EF e são aqui representadas por nomes fictícios, assim como as escolas onde lecionam. São participantes do Projeto de Pesquisa-Extensão interinstitucional (UNEMAT / SEC ${ }^{3}$ ) e interdepartamental (Letras / Pedagogia / Arte), intitulado NEPALI - Núcleo de Estudos para Professores de Arte e Língua Inglesa.

O NEPALI foi criado em 2006 com o propósito de ofertar cursos de FC aos docentes e acompanhamento sistemático às ações teórico-práticas em sala de aula. A proposta se alicerça no desenvolvimento de um tripé de competências, ou seja, uma competência teórico-linguístico-metodológica. A

\footnotetext{
${ }^{1}$ Neste estudo são considerados anos iniciais os primeiros cinco anos do Ensino Fundamental de nove anos.

${ }^{2}$ Aproveito para agradecer à profa. Dra. Ana Mariza Benedetti pelas preciosas orientações durante o doutorado, e pelas profas. Dras. Ana Antônia de Assis-Peterson, Ana Maria F. Barcelos, Maria Helena Vieira-Abrahão e Solange Aranha pelas contribuições por ocasião da qualificação e defesa.

${ }^{3}$ Secretaria Municipal de Educação.
} 
parte teórica ocorre via promoção de momentos de leitura de textos da área e reflexões, relacionando a teoria com a prática que vem sendo desenvolvida em sala. Os textos são selecionados com base nas sugestôes e dúvidas trazidas pelo grupo. Posteriormente, e ou concomitantemente, promovem-se momentos de práticas comunicativas da LI, visando ao aprimoramento da competência linguística, em que são desenvolvidas atividades diversas, com diferentes gêneros textuais que podem ser adaptados para o trabalho com os alunos em sala de aula. Por fim, o fortalecimento da competência metodológica por meio de socialização de métodos e técnicas utilizadas em sala e aquelas registradas nas pesquisas realizadas na área, bem como a elaboração e produção de materiais didáticos para uso com os alunos. Os encontros acontecem quinzenalmente (uma formação de Arte e outra de LI) e todos os participantes são estimulados a apresentar os resultados dos trabalhos em eventos organizados no município e região.

No ano da realização do estudo (2008), os professores participaram de dois eventos acadêmico-científicos: o XI Encontro de Professores de Inglês $(E P I)^{4}$ e VI Colóquio de Letras 5 . Neste último, o Projeto participou da organização com uma exposição de trabalhos de Arte e LI - Mostra NEPALI - desenvolvidos por professores e alunos das escolas da REME. Para a coleta dos dados foram realizados dois questionários (Q) - um no início do ano letivo e um logo após a participação no EPI -, entrevistas individuais com cada uma das participantes (E), quatro sessões reflexivas (SR), realizadas bimestralmente, entre as docentes e a pesquisadora $(\mathrm{Pq})$, gravadas em áudio e vídeo e sete logs $(\mathrm{L})$ - respondidos após o término de cada encontro. Também houve acompanhamento sistemático nas escolas onde as docentes lecionam, especificamente em classes do primeiro e do quinto anos, além do curso de FC, ofertado pelo Projeto NEPALI.

Ainda que consideraçôes sobre formação docente sejam apresentadas neste artigo em seçôes diferentes, considero-a como processo amplo chamado de "processo de desenvolvimento profissional docente" (ver, por exemplo, DUTRA; MELLO, 2004). Tal processo veicula a ideia de um percurso

${ }^{4} \mathrm{O}$ EPI é um encontro regional, realizado anualmente pela APLIEMT (Associação Matogrossense de professores de Língua Inglesa) e acontece de forma itinerante em diferentes instituições de Ensino Superior do estado. Em 2008 o evento aconteceu na capital Cuiabá.

${ }^{5}$ O Colóquio de Letras é um evento local e acontece anualmente na UNEMAT. 
profissional, cuja trajetória não é linear (FI + exercício da profissão + FC), mas evolutiva em um continuum de experiências marcadas por fatores diversos, como sociais, políticos, pessoais e familiares que atuam como influências facilitadoras ou dificultadoras do processo de aprendizagem da profissão.

\section{Formação inicial: alguns apontamentos}

Pressupostos delineados para a FI em outras áreas podem, mediante devidas adaptações, prover subsídios teóricos e práticos em busca de uma FI também para o docente de LI para anos iniciais. As instituiçôes responsáveis pela FI têm papel decisivo na promoção do conhecimento profissional e dos aspectos da profissão docente, comprometendo-se com o contexto e a cultura em que esta se desenvolve. Já que o Curso de Pedagogia é o locus privilegiado para a ocorrência da formação de professores, muitas de minhas considerações mantêm vínculos com pressupostos voltados a esse curso. As considerações vinculadas ao Curso de Letras se justificam pelo fato deste ser o responsável pela formação do profissional de línguas.

As Diretrizes Curriculares para o Curso de Pedagogia (Resolução CNE/ CP No 1/2006) compreendem a docência como ação educativa e processo pedagógico metódico e intencional, construído em relações sociais, étnicoraciais e produtivas, as quais influenciam conceitos, princípios e objetivos da Pedagogia, desenvolvendo-se na articulação entre conhecimentos científicos e culturais, valores éticos e estéticos inerentes a processos de aprendizagem, de socialização e de construção do conhecimento, no âmbito do diálogo entre diferentes visões de mundo. A FI no Curso de Pedagogia visa, de acordo com o Projeto Pedagógico do Curso de Pedagogia da UNEMAT - Universidade que forma a maioria dos profissionais onde o estudo foi desenvolvido -, capacitar / formar o docente como profissional responsável para atuar com alunos da Educação Infantil (EI), primeiro ao quinto anos e matérias pedagógicas para formação docente, proporcionando instrução didáticopedagógica para lidar com a clientela.

De acordo com análise feita nos documentos existentes no Departamento de Pedagogia, a Grade Curricular antiga (1997) sofreu adequações em 2006/ 01 e, em 2007/02, entrou em vigor uma nova. Nos documentos anteriores a 2007, o curso oferecia também disciplinas optativas / eletivas que, mediante consenso dos acadêmicos e um número mínimo de cursistas (25), podiam ser instituídas. Importa mencionar que havia duas disciplinas optativas, de 60 horas cada, a saber, LI e Língua Espanhola, cuja responsabilidade didático- 
pedagógica recaía para o Curso de Letras. Desde a implantação do Curso (1990), somente no segundo semestre de 2007 houve turma para que a disciplina fosse oferecida. No entanto, embora nas escolas públicas municipais a oferta se restrinja ao ensino de LI, a procura foi pela Língua Espanhola. A Matriz prevê, ao professor pedagogo, o recebimento de formação didática para lidar com crianças, mas, ainda que curse uma disciplina específica em LE, é insuficiente para desenvolver sua competência linguística e metodológica.

Em contraste, aparece o professor formado em Letras, cuja graduação centra-se na Linguística como se pode apreender da Matriz Curricular do Curso de Licenciatura em Letras da UNEMAT (2006). Esse Curso forma professores para atuar nas áreas de LP, LI e Literaturas, do sexto ao nono anos e EM, mas, mediante consulta nas Diretrizes Curriculares, não oferece disciplina de capacitação especificamente para anos iniciais, carecendo, assim, de enfoque metodológico para lidar com crianças.

De acordo com as Diretrizes Curriculares Nacionais para o curso de Letras (CNE/CES 492/2001, p. 29) o graduado "deverá ser identificado por múltiplas competências e habilidades adquiridas durante sua formação acadêmica convencional, teórica e prática, ou fora dela" que demandem "o domínio da língua estudada e suas culturas para atuar como professores, pesquisadores, críticos literários, tradutores, intérpretes" dentre outras atividades. As competências e habilidades mencionadas no documento apontam para o domínio da LP ou de uma LE, nas suas manifestações oral e escrita; reflexão analítica e crítica sobre a linguagem como fenômeno psicológico, educacional, social, histórico, cultural, político e ideológico; visão crítica das perspectivas teóricas adotadas nas investigações linguísticas e literárias; preparação profissional atualizada; utilização dos recursos da informática; domínio dos conteúdos básicos e dos métodos e técnicas pedagógicas que permitam a transposição dos conhecimentos para os diferentes níveis de ensino.

\section{Formação contínua: o professor enquanto aprendiz permanente}

Nos últimos anos, tem havido, na área educacional, uma tendência de se atentar para o processo prático, à luz de teorias, em busca de melhorias do desempenho dos profissionais ligados à educação. Há uma necessidade urgente de se repensar a FI e continuada de docentes, haja vista as novas demandas da contemporaneidade. Isso implica rever, sobretudo, o papel da escola, do professor, dos alunos, das políticas educacionais públicas, das práticas 
pedagógicas, das concepçóes de ensino-aprendizagem, linguagem e conhecimento. Corroborando ideias de Falsarella (2004, p. 50), a FC é entendida como "proposta intencional e planejada, que visa a mudança do educador através de um processo reflexivo, crítico e criativo" e "motivar o professor a ser ativo agente na pesquisa de sua própria prática pedagógica, produzindo conhecimento e intervindo na realidade".

Giovanni (2003), por exemplo, defende uma proposta de 'formação centrada na escola' ou de 'formação-ação'. Essa proposta tem por objetivo integrar situaçóes de FC e de trabalho e parte do pressuposto de que, vivenciando situações que integram formação, investigação e ação, o profissional muda, mudando, também, o contexto em que trabalha.

É notório um distanciamento entre a FI do professor e sua atuação prática diante das demandas educacionais advindas do contexto em que está inserido, o que consolida a necessidade de uma educação contínua em serviço, independentemente das condiçóes nas quais efetuou a FI e da situação da escola em que leciona, enfatiza Bettega (2004), não apenas para ficar atualizado em sua área, dada a velocidade e o dinamismo com que o conhecimento é produzido num curto espaço de tempo, mas pela própria natureza do fazer pedagógico. Minhas ideias são convergentes com as dos autores aqui abordados, no que diz respeito ao caráter coletivo, colaborativo e participativo da formação permanente e esse tipo de formação não pode ser entendido "apenas como atualização científica, pedagógica e cultural do professor, e sim, sobretudo como a descoberta da teoria para organizá-la, fundamentá-la, revisála e concebê-la, se preciso" (IMBERNÓN, 2005, p. 69).

A FC não é um prolongamento da formação inicial, meio de adaptação às mudanças ocorridas ou a serem implementadas na instituição ou ainda sinônimo de educação compensatória. Reuniōes esporádicas, minicursos, simpósios, ministrados quando se deseja implantar novos métodos ou técnicas, não têm ajudado a melhorar a qualidade nem a resolver problemas básicos que afetam diariamente a atuação docente e o resultado do ensino. Pelo contrário, a FC pode contemplar seminários de observação mútua, espaços de prática reflexiva, laboratórios de análise coletiva das práticas e dispositivos de supervisão dialógica, em que os supervisores são parceiros e interlocutores (NÓVOA, 2001).

Nas Orientações Gerais da Rede Nacional de FC de Professores (2005), princípios e diretrizes norteadores do processo são descritos. Essas diretrizes definem FC como exigência da atividade profissional no mundo atual tendo 
como referência a prática docente e o conhecimento teórico. Afirmam ainda que a FC vai além da oferta de cursos de atualização e que para ser continuada deve integrar-se no dia a dia da escola. No que diz respeito aos sistemas formais de oferta de FC, na página virtual do $\mathrm{MEC}{ }^{6}{ }^{6}$ é possível encontrar diferentes programas que fazem parte da política de FC que vem sendo desenvolvida desde 2003. Em Mato Grosso, a Secretaria de Estado de Educação desenvolve programas. ${ }^{7}$ Todavia, até a presente data, nenhum dos sistemas formais contempla a formação de docentes de LI.

Quando se discorre acerca da FC de docentes de LI, Rodrigues (2003) tece considerações sobre linhas norteadoras de trabalho. A autora defende um curso de FC que promova estudo sobre preocupaçôes e inquietaçóes teóricas acerca da natureza da linguagem, aprendizagem e organização do ensino e viabilize reflexões sobre a prática docente. A atuação do formador consiste na promoção de situações nas quais o professor possa estabelecer conexões entre o conhecimento adquirido e o experimental, que podem desencadear modelos que aproximem teoria e prática. Essa autora preconiza uma FC que procure balancear momentos em que os professores apresentem seus planejamentos de curso, planos de aula e atividades propostas aos alunos, momentos de apresentação de propostas de atividades de LE e momentos de discussões a fim de desencadear reflexões teórico-metodológicas.

\section{Linguística Aplicada: caminhos em busca de formação docente e ensino-aprendizagem relevantes}

Há um consenso entre estudiosos da área de LA (DUTRA; MELLO, 2004; FARIAS et al., 2008; ALLRED, 2008; MAGALHÃES; FIDALGO, 2008; GIMENEZ et al., 2008; VIEIRA-ABRAHĀO, 2007, dentre outros), especialmente no que se refere à formação docente, de que reflexão e colaboração são conceitos chaves para o desenvolvimento do professor. Reconhecem também que há uma relação intrincada entre a teoria e o fazer pedagógico, além da dificuldade de romper com abordagens que privilegiam a transmissão em detrimento da construção de conhecimentos. Para Gimenez et al. (2008, p. 304), o paradigma reflexivo de formação "requer estruturação de práticas a partir de análises contextualizadas de ensino". Elas relatam que

${ }^{6}$ Disponível em: <http://portal.mec.gov.br>. Acesso em: 12 fev. 2008.

${ }^{7}$ Disponível em: < http://www.seduc.mt.gov.br>. Acesso em: 13 fev. 2008. 
algumas iniciativas têm sido tomadas quanto à FC no Paraná, por exemplo, que incluem vinculação entre FI-FC e envolvimento de instituições de ensino superior e rede privada de ensino de LI, culminando naquilo que chamam de "rede de instituições formadoras". Veem na pesquisa, especialmente a participativa, um caminho para que a reflexão aconteça.

Dutra e Mello também relatam experiências de projetos de FI (PROFIPLI) e FC (EDUCONLE) por elas desenvolvidos, cujos pressupostos teóricos e metodológicos se baseiam em processos reflexivos e participativos. Visam ao desenvolvimento de atividades de cunho reflexivo, pois sem ele "a prática dos professores pode estagnar e ser somente uma reprodução nãosituada socialmente de ações pedagógicas" (DUTRA; MELLO, 2004, p. 41). Magalhães e Fidalgo (2008, p. 107), igualmente acreditam que a pesquisa colaborativa é uma escolha metodológica plausível para programas de educação contínua que envolvam sujeitos diretamente ligados ao contexto escolar.

Por semelhante modo, Allwright (2008) e Miller et al. (2008) defendem a Prática Exploratória como possível caminho para uma FI de docentes, caracterizada por atitudes reflexivas. Ao lado da Pesquisa-Ação e a Colaborativa, ela aparece como outro caminho possível com base em "uma proposta de desenvolvimento profissional que, buscando o entendimento dos porquês pré-existentes à qualidade de vida que se vive em sala de aula, não adota uma postura tecnicista voltada para o produto, para a mudança de técnicas de ensino" (p. 155).

Diante da imensidão de pesquisas disponíveis nas mais diversas áreas do conhecimento, e especificamente na Educação, Letras e Linguística, percebese que aquelas direcionadas ao ensino-aprendizagem e formação docente em Língua Estrangeira para crianças (LEC) correspondem a um número muito reduzido. Com o intuito de obter uma visão das principais pesquisas desenvolvidas na área, especialmente a partir do início da década passada, apresento algumas contribuiçóes a que tive acesso ${ }^{8}$ durante o desenvolvimento deste estudo. Inspirada em Barcelos (2007), apresento-os de acordo com o foco, em três grupos:

No primeiro grupo, o foco centra-se em metodologias de ensino e avaliação, nos trabalhos (sobretudo dissertações) de Szundy (2001), Figueira

\footnotetext{
${ }^{8}$ A maioria dos estudos é proveniente do mapeamento feito pelo LEC, um grupo de discussão em ambiente virtual, formado por professores / pesquisadores e moderado por Claudia Hilsdorf Rocha.
} 
(2002), Santos (2002), Luz (2003), Roselli (2003), Villani (2003), Carvalho (2005), Marins (2005), Tonelli (2005), Scaffaro (2006), Tambosi (2006), Costa (2008), Lima (2008), dentre outros. De forma geral, esses estudos adotam a pesquisa qualitativa (de cunho etnográfico e interpretativista) como pressuposto metodológico e selecionaram crianças de dois a dez anos e docentes provenientes de escolas públicas, privadas ou de idiomas, nas áreas de LI e Língua Espanhola para comporem o quadro de participantes. Sobressaem-se as entrevistas e gravações em áudio e vídeo, testes, diários e observação participante como instrumentos de coleta. Os objetivos priorizam investigação, identificação e análise de abordagens de ensino dos docentes, de exame avaliativo, origem das motivações das crianças para o aprendizado de LE, uso de brincadeiras e histórias infantis. Os principais resultados obtidos mostram que as motivações são produtos de construçôes sociais desenvolvidas no processo de interação das crianças com ambientes escolar e familiar e que a interação com pares mais eficientes nos jogos de linguagem contribui para a socioconstrução de alguns objetos linguísticos específicos na LE; os jogos de leitura colaboram para o ensino-aprendizagem de LI, em que se evidencia influência positiva da conduta didática do docente investigado. No que concerne ao exame avaliativo analisado, o estudo mostra que não encontra consonância com as concepçõos e objetivos oficialmente estabelecidos para o EF.

O segundo grupo focaliza a formação do professor e é representado por trabalhos de Cunha (2003), Claus (2005), Shimoura (2005), Rinaldi (2006) e Costa (2007), por exemplo. Como já evidenciado, a natureza da pesquisa adotada é a qualitativa (interpretativista e crítico-colaborativa), os instrumentos selecionados são observações participantes, entrevistas e gravações em áudio e vídeo e questionários, com docentes de LI e Língua Espanhola. Objetivam analisar como o curso de Letras apresenta teorias de ensino-aprendizagem e como ocorre a formação de docentes de LE para crianças, verificar como um curso contribui para a mudança da prática, além de discutir a introdução de LE em anos iniciais. Em geral, os resultados obtidos apontam que, para o docente atuar satisfatoriamente na sociedade contemporânea, é indispensável FI e FC crítico-reflexivas que abarquem conhecimentos teórico-metodológicos e que os professores estejam abertos a mudanças, o que implica envolvimento com seus pares, de diferentes formas. Eles também denunciam a falta de habilitação docente para atuação em LEC e urgência na ampliação de leis que os regulamentem, o que pode minimizar dificuldades encontradas nas práticas cotidianas. 
Por fim, os trabalhos de base qualitativa de Santos (2005), Rocha (2006) e Scheifer (2008) tratam de crenças de diferentes participantes sobre o ensino de LEC. Apresentam como objetivos a descrição e compreensão de crenças de professores e outros participantes de contextos escolares específicos e elaboração de justificativas e provisões teóricas para a condução do ensino de LI no EF. Os resultados apontam que a inclusão de LI nas séries iniciais é benéfica e importante, mas que não funciona satisfatoriamente, especialmente na escola pública, por várias razões, dentre elas, a falta de professores devidamente preparados e condiçóes materiais. Denunciam necessidade de discussão teórica abrangente para pensar e implementar políticas educacionais de ensino de LE que colaborem para a formação de indivíduos bem preparados para atuar na sociedade brasileira contemporânea. Sugerem elaboração de diretrizes teórico-práticas específicas para o ensino-aprendizagem de línguas a esse público e investigação mais profunda a respeito das crenças e objetivos dos alunos, professores e terceiros, tornando-o mais próximo das expectativas e mais significativo.

Essa rápida explanação sobre algumas propostas de formação de professores de línguas me permite concluir que há uma necessidade eminente de se somar esforços, para implementarmos cada vez mais programas que levem em consideração o caráter indissociável do binômio FI-FC.

\section{Compreendendo a importância da formação contínua na vida profissional docente}

As cinco participantes deste estudo são unânimes em dizer que a FI deixou lacunas, mesmo porque, não receberam formação para atuar no ensino de LI para crianças. No entanto, também são unânimes ao entenderem a formação como um processo não linear, sempre em construção, conforme apresentei na introdução. Olhando atentamente para os dados, pude inferir que, para elas, FI, FC, experiência e o fazer pedagógico são elementos marcantes em sua vida profissional, que se relacionam de forma interdependente. Além de considerar as especializações cursadas pelas docentes um tipo de FC que buscaram para 'sanar' lacunas da FI ou aprimorar os conhecimentos lá construídos, concentro meus esforços neste texto na análise de duas fontes vivenciadas no decorrer do ano letivo em que a coleta de dados ocorreu, a saber, a participação das docentes na FC ofertada pelo Projeto NEPALI e em dois eventos científicos: o XI Encontro de Professores de Inglês (EPI) e VI Colóquio de Letras. 
Para abarcar considerações sobre a FC trago dados procedentes do primeiro questionário, entrevistas, relatórios do projeto NEPALI, sessões reflexivas e logs. É pertinente iniciar apresentando o conceito de FC mencionado pelas participantes. Nesse sentido, para elas FC é:

(01) aquela que fazemos para sanar dúvidas, angústias e troca de experiências com profissionais. Consegue contribuir para dinamizar aulas, não ficar ultrapassado. (Verdade, Q1, 21/02/2008); ${ }^{9}$

(02) estar em busca constante, ou seja, troca de experiências, comentar / levantar problemas e buscar ajuda, sanar dúvidas e que esta FC contribua para nosso fazer pedagógico. (Tuchi, Q1, 21/02/2008);

(03) processo de capacitação contínuo, sempre que surgir dúvidas buscar orientaçôes, participar dos encontros. É importante a contribuição no fazer pedagógico, pois formação é troca de experiência. (Nati, Q1, 21/02/2008);

(04) é um processo contínuo que estamos sempre em busca e troca de informaçóes e experiências. Contribui nos aspectos de crescimento no conhecimento e no desenvolvimento pedagógico. (Analu, Q1, 21/02/2008);

(05) atualização permanente, faz parte do estudo linguístico e metodológico que torna o professor mais criativo. (Coralina, Q1, 21/02/2008).

Parece, pois, que o conceito que defendem para o termo alinha-se à perspectiva que toma o professor como aprendiz permanente, definidos por Falsarella (2004), Giovanni (2003), dentre outros. Alguns aspectos se sobressaem: primeiramente, a FC 'deve partir da necessidade', ou seja, para as docentes, a FC só faz sentido se tiver isso como força motriz. No caso desse grupo, a 'necessidade' justifica-se pela ausência de FI adequada para atuação com crianças, o que as leva a dialogar com pares que tenham leituras e experiências na área para que sejam compartilhadas, como fica evidente nos excertos descritos acima.

Quando questionadas sobre os motivos que as levam deixar sua hora atividade para participar da FC, são unânimes ao afirmar que o principal delas

\footnotetext{
${ }^{9}$ Tanto as professoras quanto as escolas receberam nomes fictícios. A transcrição das entrevistas e sessōes reflexivas reproduziu o modo oralizado da fala dos participantes (MARCUSCHI, 1999).
} 
é a socialização das práticas pedagógicas, o que "ajuda muito na sala de aula, ao trabalhar vocabulário, naquilo que tem dificuldade, para poder ter mais segurança na aula"; na tentativa de explicar que tudo "chama sua atenção" durante a FC, Verdade (E1, 06/07/2008) assevera que, ao se trabalhar sozinha, as ideias vão se esgotando e / ou tornando-se repetitivas, precisando de contato com outros profissionais da área para que mudanças possam ocorrer na prática cotidiana. O mesmo acontece com Coralina, que vê também na FC um momento para rever amigos, o que contribui não só para o desenvolvimento profissional, bem como para o pessoal. Nati, por sua vez, afirma encontrar na FC subsídios para inovações em sala de aula e Tuchi nota que suas angústias não são únicas, além de usar os materiais e ideias que são discutidas nos momentos de formação:

(06) $[t] \mathrm{raz}$ um encontro entre mais profissionais que pensam e estão envolvidos na mesma situação pedagógica que é o fazer, o ensinar em termos de LE, um profissional ajuda o outro, um professor dá uma ideia, outro complementa, há esse entrosamento legal, bom mesmo / .../ só de rever a pessoa é uma alegria. (Coralina, E3, 10/07/2008).

(07) [...] é tudo, quando eu tenho uma dúvida pergunto e percebo que as minhas angústias são as angústias das colegas, as atividades, os jogos, os textos, as mensagens, a questão de vocês fornecerem materiais, NOSSA. (Tuchi, E5, 29/09/2008).

Para as professoras investigadas há uma relação intrínseca entre a FCe experiência. As discussões teóricas desencadeadas permitem um trabalho mais consciente, denominado por Verdade de "trabalho embasado" (E1, 06/07/ 2008). Coralina, Tuchi e Analu sinalizam na mesma direção, argumentando que experiência e teoria devem andar juntas. Coralina traz um elemento novo, ponderando que o fato de já ser professora, quando ainda estudava na graduação, permitiu-lhe uma consciência maior na hora de estudar teoricamente. Já Tuchi sinaliza que a ausência de formação pode levar o professor a uma "mesmice" que prejudica o desenvolvimento da disciplina, chegando a desmotivar os alunos. Amparada em Bettega (2004, p. 43), considero que esse grupo de docentes está em um processo que funciona como "matriz de percepções, tornando possível a concretização de tarefas diferenciadas", em que "o professor é capaz de tornar-se consciente das crenças, dos valores e dos conhecimentos que influenciam seu fazer e, dessa forma, ter melhores condições para modificar seu comportamento profissional". 
Consoante o trinômio formação-experiência-prática, logo nas primeiras observações, procurei atentar para a (possível) relação entre eles. Dessa forma, já na primeira aula em que acompanhei a professora Coralina, por exemplo, percebi que ela tem muita experiência com sala de aula e que isso interfere de forma positiva em seu fazer pedagógico. Demonstrou ter conhecimento de teorias de ensino aprendizagem de línguas, já que não se pauta por um ensino exclusivo de gramática-tradução, usa bastante material concreto para desenvolver sua aula, especialmente o que há na própria sala de aula.

Bettega (2004, p. 42) aponta que em muitas propostas de FC limitações são encontradas, já que os participantes ficam "responsáveis pela aplicação dos conhecimentos supostamente aprendidos em sala de aula, sem qualquer tipo de suporte dos agentes responsáveis pelo curso", o que não é o caso da formação em questão, já que não é almejada uma reflexão acerca dos elementos que envolvem a ação didática. Além do mais, pelo fato de ser contínuo mesmo, ou seja, por manter encontros regulares e visitas periódicas da equipe do projeto, os docentes sentem o suporte mencionado pela autora, como descrito por Tuchi.

No Fragmento (SR1, 01/05/2008) que segue, desencadeamos reflexões sobre a formação em que aparecem esses itens.

(08) $\mathrm{Pq}$ - tenho percebido que vocês constantemente se reportam à FC e mencionam o ensino através de dinâmicas, da ludicidade e a questão do ensino com incentivo à oralidade, mas por que que vocês se reportam somente à formação daqui e não a outros momentos da formação de vocês? Tuchi - é a questão das atividades, a maneira que você trabalha, eu não tive minha faculdade em LI, comecei um cursinho e acabei desistindo, porque não é o lúdico, não chama a atenção, acaba [desmotivando].

Coralina - [a didática] no caso a gente percebe que o professor não precisa só de conhecimento da língua, mas precisa certa didática pra conseguir pôr em prática, e isso fica aqui ((na FC)) bem visível, já é demonstrado, já participa e se adulto gosta, criança vai gostar também Analu - e por ser contínua, você tem uma dúvida lá você já corre pra sanar. Verdade - todos os cursinhos que fiz aprendi um pouco e esse pouco vem ajudando, na graduação aprendi bastante, só que aqui ele focaliza mais a prática, de primeiro ao quinto ano que pra mim era muito difícil porque nós lá ((na graduação)) nunca tivemos formação voltada pra trabalhar com crianças, quando estávamos lá nem imaginávamos que íamos trabalhar com elas, então é uma coisa que a universidade tem que pensar /.../ o mais difícil era trabalhar isso porque não tivemos alicerce pra trabalhar com crianças. 
Não só nas sessões reflexivas, bem como nas respostas aos questionamentos nos logs 1 a 5, de forma geral, as professoras justificam que as atividades desenvolvidas na FC contribuem com sugestôes metodológicas plausíveis de serem desenvolvidas em sala, melhoram a formação linguística, especialmente na pronúncia, mediante o trabalho realizado em fonética, viabilizam a motivação da criança para a aprendizagem de LI, o que as leva a considerar as propostas como plausíveis de serem colocadas em prática, contribuindo dessa forma para o planejamento e desenvolvimento das aulas, ressalvadas as devidas diferenças contextuais que requisitam adaptação.

\section{Eventos acadêmico-científicos: reflexões e expectativas}

Nesta seção apresento o que as docentes pensam acerca da participação que tiveram em encontros acadêmico-científicos, com base nos dados coletados com o segundo questionário e os logs. Socializo, primeiramente, as considerações acerca do XI EPI, em que estiveram presentes quatro das cinco docentes do estudo (exceto Tuchi que não pode participar por motivos de saúde). Os dados mostram que das quatro professoras, apenas Verdade já havia participado de eventos dessa natureza. Para ela, encontros como esse contribuem para o "crescimento intelectual e, consequentemente, refletem de forma positiva na prática pedagógica cotidiana” (Q2, 09/08/2008). A participação é impedida, na maioria das vezes, devido à distância, dificuldades financeiras, falta de informação, disponibilidade de tempo, ou, até mesmo, ausência de convite.

Há um consenso entre as professoras que esse tipo de evento é muito importante para a vida profissional, especialmente por vivermos em um mundo globalizado (ASSIS-PETERSON; COX, 2007; dentre outros). Para Coralina a participação em eventos

(09) enriquece a vida profissional e isso passa a ser uma necessidade, na atualidade /.../ aprendi que sempre temos algo a aprender e algo a ensinar e isso nos motiva a querer estudar, compartilhar, reaprender, colaborar, desafiar e se desafiar também. (Coralina, Q2, 09/08/2008).

Quando foram convidadas a dissertarem sobre o que aprenderam no encontro, as professoras parecem ter aprendido, sobretudo, a valorizarem-se como profissionais. Fica evidente, mais uma vez, a importância da troca de experiências, além da 'injeção de ânimo' para continuar no trabalho docente. Mostram ter aprendido que 
(10) devemos defender nossos direitos, lutar para conquistar cada vez mais espaço, nos empenhar para buscarmos novas informaçōes, conhecimentos, isso se dá na troca de experiências /.../ se soubermos defender nossos direitos e sermos valorizados profissionalmente, a educação dos alunos também mudará. (Nati, Q2, 09/08/2008).

Ressalto ainda que das quatro docentes, duas participaram com comunicação oral, Coralina, cuja motivação foi "o desafio de querer aprender e também compartilhar aquilo que já experimentamos e percebemos que contribui para a educação em termos de ensino-aprendizagem" e Verdade que sentiu "um grande estímulo de melhorar e acreditar em nosso trabalho cada vez mais, de levar aos alunos técnicas que para mim [ela] são novas e também novas ideias e perspectivas para meu [seu] crescimento intelectual e prático", conforme respostas reveladas pelo Q2. Nesse instrumento, registram ainda acreditar que isso pode trazer contribuições para o fazer pedagógico, como assevera Carolina, no sentido de "buscar o aperfeiçoamento, levando novidades para a sala de aula, porque percebo que o aluno também tem 'sede' de aprender, de querer algo 'diferente', inovador”. Já Verdade considera de muita importância o Projeto NEPALI, pois

(11) o inglês em anos iniciais, principalmente em escola pública é quase inédito, poucos são os municípios que têm essa disciplina na grade e ainda com aulas ministradas por professores formados na área. Outro fator muito importante que foi abordado e que choca as pessoas, é mostrar que as aulas de inglês em escola pública dão resultado e são de qualidade e o mais importante, que deixou muitos professores maravilhados com os relatos e apresentaçōes, foram os resultados, pois os alunos em anos iniciais aprendem e gostam da LI; poderia elencar vários outros, mas esses são o suficiente para continuar acreditando em nosso trabalho. (Verdade, Q2, 09/08/2008).

Evidencia-se a importância dada pela professora à implantação do ensino de LI no município em que trabalha, além da preocupação da oferta ser desenvolvida por 'profissionais da área'. Na segunda parte do excerto, Verdade expressa exatamente a atitude que observamos com vários de nossos pares, durante o evento, quando apresentamos os resultados obtidos em sala de aula, em que se mostravam "chocados", diante de evidências concretas de que, efetivamente, busca-se a oferta de ensino de LI de qualidade, embora sejam encontradas inúmeras dificuldades. 
Por semelhante modo, a parceria entre a Mostra NEPALI (algumas fotos no APÊNDICE A) e o VI Colóquio de Letras foi avaliada pelas professoras como uma "ideia excelente", o que me fez entender que haveria a participação da maioria, como de fato aconteceu. Coralina afirma que sempre sonhara com açôes como essa, ponderando que "quando era acadêmica já percebia essa necessidade porque havia uma distância muito grande entre estudantes / futuros profissionais e profissionais atuantes" (L6, 03/10/2008). Tuchi e Verdade salientam a importância de exporem o trabalho que desenvolvem em sala, colocando-o à apreciação de um público maior do que aquele restrito ao círculo do contexto educacional em que atuam. Verdade lembra ainda que é "muito importante mostrar e divulgar os resultados do trabalho, no âmbito universitário, para aqueles que ainda não concluíram a graduação e talvez não tenham ideia de como acontecem as aulas de LI em anos iniciais" (L6, 03/10/2008). Concordo com as professoras quando afirmarmam que a apreciação do trabalho por outras pessoas lhes permitiu opinar, sugerir, interagir e, consequentemente, fez com que o grupo crescesse.

$\mathrm{Na}$ avaliação ao percurso trilhado durante a FC e o envolvimento com o grupo para a coleta de dados, destaca-se, em especial:

a) oportunidade de fazer boas reflexões a respeito da prática em sala de aula;

b) motivação e preocupação em buscar constantemente meios de melhorar a qualidade do ensino-aprendizagem;

c) aprendizado de atividades diferentes, pronúncia e escrita de palavras;

d) conhecimento de novos colegas e socialização de experiências;

e) superação de obstáculos e desafios encontrados no cotidiano em sala de aula;

f) enriquecimento dos conhecimentos e desenvolvimento do trabalho com mais segurança e determinação;

g) transformação de "problemas" em "coisas boas";

h) contribuição para o crescimento pessoal e profissional.

À guisa de conclusão, registro ainda que é nosso desejo (do grupo de docentes de LI e meu) que a FC continue sendo ofertada nas várias modalidades, além da inclusão de FI para atuação com crianças, oportunizando o desenvolvimento profissional. Corroboro, pois, o desejo de Analu "de continuarmos os encontros e que serão melhores que este ano, porque à medida que o tempo passa, surgem novos desafios e obstáculos e precisamos estar em constante busca 
de ideias, soluções e, acima de tudo, novos conhecimentos para superá-los" (L7, 03/11/2008).

\section{Considerações Finais}

A habilitação em LE é indispensável para o alcance de resultados satisfatórios no ensino de LI para crianças e deve contemplar embasamento teórico-metodológico e sociocultural que possibilite compreender o que é língua(gem) e ensino-aprendizagem, pois essa compreensão interfere na prática docente (VIEIRA-ABRAHÃO, 2004). A discussão mostra que, embora a FI seja muito importante, não é suficiente para dar conta do perfil requerido ao profissional da educação na sociedade contemporânea. Nesse sentido, ponderei acerca da necessidade de uma interface entre as FI e FC com a experiência pessoal e profissional de cada docente. A mudança na formação do professor de LI para crianças se justifica por, pelo menos, dois motivos:

Primeiro motivo: a oferta de graduaçôes existentes na atualidade não contempla a formação específica para atuação com LI para crianças. Compreendo que uma formação docente adequada deva dar conta tanto da aquisição do idioma inglês, quanto das formas de ensiná-lo, com vistas a uma aprendizagem significativa, conforme apontam defensores de uma aprendizagem sociointeracionista (VYGOTSKY, 2001, por exemplo). Concordo com Rinaldi (2006, p. 149), quando assevera não defender outro tipo de formação, mas, sim, que os já existentes possam contemplar disciplinas capazes de ajudar o professor a desempenhar sua função.

Algumas ações isoladas têm acontecido e são bem-vindas. No caso do curso que forma a maioria dos docentes da região onde o estudo foi realizado (UNEMAT), discussões têm culminado em mudanças, ainda que modestas, como é o caso da inclusão da literatura que trata da oferta de ensino de LI para crianças nas disciplinas de LA ao ensino de LE, nas próprias ações de sala de aula, durante o desenvolvimento das aulas de LI ao longo do curso e em outras disciplinas diretamente relacionadas aos aspectos didáticos (Didática e de Estágios Curriculares Supervisionados).

Outras ações são vistas mediante oferta de especializações Lato sensu em ensino-aprendizagem de LE, cujas matrizes já contemplam disciplinas específicas para o ensino em diferentes idades. Outras vezes, ainda mediante oferta de cursos, oficinas ou programas de FC, por exemplo, o Projeto NEPALI. Entretanto, nenhum tipo de investimento oficial por parte dos 
órgãos governamentais responsáveis pela educação, como o MEC, Secretarias de Educação Estaduais e Municipais, foi feito até o momento, no sentido de implantar políticas públicas que regulamentem a oferta e, por conseguinte, invistam em FI e FC.

Dessa forma, vejo como possíveis caminhos a continuação de realização de pesquisas na área e divulgação, no meio acadêmico e social como um todo, das ações desenvolvidas nos contextos em que aparece o ensino de LI, especialmente o público, e sistematização dessas, por meio das associações de docentes de LI (por exemplo, APLIESP, APLIEMT), pois estas têm mais força do que ações isoladas de docentes, além de oportunizar-lhes condições para que se sintam protagonistas do processo.

Segundo motivo: as matrizes vigentes dos cursos que contemplam a formação docente ainda não evoluíram satisfatoriamente. A 'simples' oferta de cursos não é suficiente para uma formação sólida. É, pois, necessária uma discussão mais ampla que considere, além do binômio teoria-prática, sua indissociável relação com o conhecimento de aspectos social e cultural de indivíduos que se moldam e são moldados em suas práticas.

Concluo que, embora as docentes tenham apresentado dificuldades para desenvolver as aulas de LI para crianças, não mediram esforços para saná-las, em que se sobressaíram ações desenvolvidas nos momentos de FC no Projeto NEPALI, no compartilhar experiências e angústias, que, sem dúvida, proporcionaram e continuam a proporcionar, a construção de importantes conceitos e conhecimentos sobre a docência nessa área e faixa etária específicas. Destaco a importância do Projeto para as docentes e para mim, como professora-formadora e pesquisadora, porque percebo que o envolvimento no processo de formação com base reflexiva nos motiva a buscar cada vez mais melhorias pessoais e profissionais e, com o desenvolvimento de um trabalho bem-sucedido, conseguimos mostrar para o próprio grupo de professores, para a comunidade escolar para a sociedade em geral, a importância da disciplina, desencadeando sua valorização e autovalorização. 


\section{Referências}

ALLRED, C. Critical Media Literacy: a $21^{\text {st }}$ Century Teaching Tool. In: GIL, G.; VIEIRA-ABRAHÃO, M. H. Educação de professores de línguas: os desafios do formador. Campinas: Pontes Editores, 2008. p. 91-104.

ALLWRIGHT, D. Prioritizing the Human Quality of Life in the Language Classroom: is it Asking Too Much of Beginning Teachers? In: GIL, G.; VIEIRAABRAHÃO, M. H. Educação de professores de línguas: os desafios do formador. Campinas: Pontes Editores, 2008. p. 127-144.

ALMEIDA FILHO, J. C. P. Ontem e hoje no ensino de línguas no Brasil. In: STEVENS, C. M. T.; CUNHA, M. J. C. (Org.). Caminhos e colheitas: ensino e pesquisa na área de inglês no Brasil. Brasília: Editora Universidade de Brasília, 2003. p. 19-34.

ASSIS-PETERSON, A. A.; COX, M. I. P. Inglês em tempos de globalização: para além de bem e mal. Calidoscópio. v. 5, n. 1, p. 5-14, 2007.

BARCELOS, A. M. F. Crenças sobre ensino e aprendizagem de línguas: reflexões de uma década de pesquisa no Brasil. In: ALVAREZ, M. L. O.; SILVA, K. A. (Org.). Linguística aplicada: múltiplos olhares. Campinas: Pontes, 2007. p. 27-70. BETTEGA, M. H. Educação continuada na era digital. São Paulo: Cortez, 2004. BRASIL. Diretrizes Curriculares Nacionais para o Curso de Letras. Brasília: CNE/ CES, 492/2001.

BRASIL. Diretrizes Curriculares Nacionais para o Curso de Pedagogia. Brasília: CNE/ CP, $1 / 2006$.

BRASIL. Rede Nacional de Formação Continuada de Professores da Educação Básica: Orientaçōes Gerais. Brasília: MEC/SEB, 2005.

CARVALHO, R. C. M. A teacher's discourse in EFL classes for very Young learners: investigating mood choices and register. Florianópolis: 2005, 119 f. Dissertação (Mestrado em Letras) - Universidade Federal de Santa Catarina, 2005.

CLAUS, M. M. K. A formação da competência teórica do professor de língua estrangeira: o que revelam os estágios. Campinas: 2005. Dissertação (Mestrado em Linguística Aplicada) - Instituto de Estudos da Linguagem, Universidade Estadual de Campinas, 2005.

COSTA, L. P. Uso de um exame internacional de proficiência em lingua inglesa para crianças no ensino fundamental brasileiro. Campinas: 2008. Dissertação (Mestre em Linguística Aplicada) - Instituto de Estudos da Linguagem, Universidade Estadual de Campinas, 2008. 
COSTA, R. V. Pode ser em inglês? Não. Em português primeiro: ensino de língua inglesa para crianças em contextos emergentes no país: um estudo de caso. Campinas: 2007. Tese (Doutorado em Linguística Aplicada) - Instituto de Estudos da Linguagem, Universidade Estadual de Campinas, 2007.

CUNHA, A. M. A. A prática reflexiva do professor de inglês: mudanças de representaçōes e construção de identidades. São Paulo: 2003, 138 f. Dissertação (Mestrado em Linguística Aplicada e Estudos da Linguagem) - Pontifícia Universidade Católica de São Paulo, 2003.

DUTRA, D. P.; MELLO, H. A prática reflexiva na formação inicial e continuada de professores de língua inglesa. In: VIEIRA-ABRAHÃO, M. H. (Org.). Prática de ensino de lingua estrangeira: experiências e reflexōes. Campinas: Pontes/Arte Língua, 2004. p. 31-43.

FALSARELLA, A. M. Formação continuada e prática de sala de aula: os efeitos da formação continuada na atuação do professor. Campinas: Associados, 2004.

FARIAS, M. et al. Sociocultural and Political Issues in English Teacher Education: Polices and Training in Argentina, Brazil, Chile and Colombia. In: GIL, G.; VIEIRA-ABRAHÃO, M. H. Educação de professores de linguas: os desafios do formador. Campinas: Pontes, 2008. p. 23-44.

FIGUEIRA, C. D. S. Crianças alfabetizadas aprendendo lingua estrangeira. Brasília: 2002. Dissertação de Mestrado - Faculdade de Letras, Universidade de Brasília, 2002.

GIMENEZ, T. et al. A pesquisa participativa no desenvolvimento profissional de formadores de professores de inglês. In: GIL, G.; VIEIRA-ABRAHÃO, M. H. Educação de professores de línguas: os desafios do formador. Campinas: Pontes Editores, 2008. p. 303-318.

GIOVANNI, L. M. O ambiente escolar e ações de formação continuada. In: TIBALLI, E. F. A.; CHAVES S. M. (Org.). Concepções e práticas em formação de professores: diferentes olhares. Rio de Janeiro: DP\&A, 2003. p. 207-224.

IMBERNÓN, F. Formação docente e profissional: formar-se para a mudança e a incerteza. 5. ed. São Paulo: Cortez, 2005.

LIMA, A. P. O ensino de inglês na educação infantil: um estudo exploratório. São Carlos: 2008, 102f. Monografia (Licenciatura em Letras) - Centro de Educação e Ciências Humanas, Universidade Federal de São Carlos, 2008.

LUZ, G. A. O ensino de inglês para crianças: uma análise das atividades em sala de aula. Goiânia: 2003. Dissertação (Mestrado) - Faculdade de Letras, Universidade Federal de Goiás, 2003. 
MAGALHÃES, M. C. C.; FIDALGO, S. S. Teacher Education Language in Collaborative and Critical Reflective Contexts. In: GIL, G.; VIEIRAABRAHÃO, M. H. Educação de professores de línguas: os desafios do formador. Campinas: Pontes, 2008. p. 105-124.

MARCUSCHI, L. A. Análise da conversação. São Paulo: Ática, 1999.

MARINS, I. M. M. O contexto social na motivação de crianças aprendizes de uma lingua estrangeira. Pelotas: 2005, 113 f. Dissertação (Mestrado em Letras) Universidade Católica de Pelotas, 2005.

MATO GROSSO. Projeto Pedagógico do Curso de Letras: UNEMAT, 2006

MATO GROSSO. Projeto Pedagógico do Curso de Pedagogia: UNEMAT, 1997.

MILLER, I. K. et al. Prática exploratória: questões e desafios. GIL, G.; VIEIRAABRAHÃO, M. H. Educação de professores de línguas: os desafios do formador. Campinas: Pontes Editores, 2008.

NÓVOA, A. Professor se forma na escola. Revista Nova Escola, ed. 142, 2001. Disponível em: <http://novaescola.abril.com.br/ed/142_mai01/html/ fala_mestre.htm>. Acesso em: 18 fev. 2008.

RINALDI, S. Um retrato da formação de professores de espanhol como língua estrangeira para crianças: um olhar sobre o passado, uma análise do presente e caminhos para o futuro. São Paulo: 2006. 171 f. Dissertação (Mestrado em Educação) - Faculdade de Educação, Universidade de São Paulo.

ROCHA, C. H. Provisôes para ensinar LE no ensino fundamental de $1^{a}$ a $4^{a}$ séries: dos parâmetros oficiais e objetivos dos agentes. Campinas: 2006. Dissertação (Mestrado em Linguística Aplicada) - Instituto de Estudos da Linguagem, Universidade Estadual de Campinas, 2006.

RODRIGUES, L. A. D. Formação continuada em língua inglesa. In: CARVALHO, A. M. P. Formação continuada de professores: uma releitura das áreas de conteúdo. São Paulo: Pioneira Thomson Learning, 2003. p. 143-153.

ROSELLI, B. R. Planejamento colaborativo: o desenvolvimento da autonomia do professor em relação ao livro didático. São Paulo: 2003. Dissertação (Mestrado em Linguística Aplicada e Estudos da Linguagem) - LAEL/PUCSP, 2003.

SANTOS, L. I. S. Lingua Inglesa em anos iniciais do Ensino Fundamental: fazer pedagógico e formação docente. São José do Rio Preto: 2009, 274 f. Tese (Doutorado em Estudos Linguísticos) - Instituto de Biociências, Letras e Ciências Exatas, Universidade Estadual Paulista, 2009.

SANTOS, L. I. S. Crenças acerca da inclusão de lingua inglesa nas séries iniciais: quanto antes melhor? Cuiabá: 2005, 230f. Dissertação (Mestrado em Estudos Linguísticos) - Instituto de Linguagem, Universidade Federal de Mato Grosso, 2005. 
SANTOS, M. E. B. Ensino de inglês para crianças: uma proposta construtivista. Assis: 2002. Dissertação (Mestrado) - Faculdade de Ciências e Letras, Universidade Estadual de Assis, 2002.

SCAFFARO, A. P. O uso da atividade de contar histórias como recurso na retenção de vocabulário novo na língua inglesa com crianças na fase pré-escolar. São Leopoldo: 2006, 117 f. Dissertação (Mestrado em Línguística Aplicada) - Centro das Ciências da Comunicação, Universidade do Vale dos Sinos, 2006.

SCHEIFER, C. L. Ensino de Lingua Estrangeira para crianças: entre "o todo" $e$ "a parte": uma análise da dinâmica das crenças de uma professora e de seus alunos. Pelotas: 2008, 210 f. Dissertação (Mestrado em Letras) - Universidade Católica de Pelotas, 2008.

SHIMOURA, A. S. Projeto de formação de professores de inglês para crianças: o trabalho do formador. São Paulo: 2005, $184 \mathrm{f}$. Tese (Doutorado em Linguística Aplicada e Estudos da Linguagem), PUC/SP, 2005.

SZUNDY, P. T. C. Os jogos no ensino-aprendizagem de lingua estrangeira para crianças: a construção do conhecimento através de jogos de linguagem. Dissertação (Mestrado), PUC/SP, 2001.

TAMBOSI, H. H. F. Investigating language play in interaction: a qualitative study with children as foreign language learners. Florianópolis: 2006, 79 f. Dissertação (Mestrado em Letras) - Universidade Federal de Santa Catarina, 2006.

TONELLI, J. R. A. Histórias infantis no ensino da língua inglesa para crianças. Londrina: 2005, 270 f. Dissertação (Mestrado em Estudos da Linguagem) Universidade Estadual de Londrina, 2005.

VIEIRA-ABRAHÃO, M. H. A formação inicial do professor de língua estrangeira: parceria universidade e escola pública. In: ALVAREZ, M. L. O.; SILVA, K. A. (Org.). Linguistica aplicada: múltiplos olhares. Campinas: Pontes, 2007. p. 155-166.

VIEIRA-ABRAHÃO, M. H. (Org.). Prática de ensino de língua estrangeira: experiências e reflexões. Campinas: Pontes, Arte Língua, 2004.

VILLANI, F. L. O processo de transformação na elaboração e aplicação de um material didático. São Paulo: 2003. Dissertação (Mestrado em Linguística Aplicada e Estudos da Linguagem) - LAEL/PUCSP, 2003.

VYGOTSKY, L. S. A Construção do pensamento e da linguagem. São Paulo: Martins Fontes, 2001. 


\section{Apêndice A \\ Algumas fotos da 'MOSTRA NEPALI'}

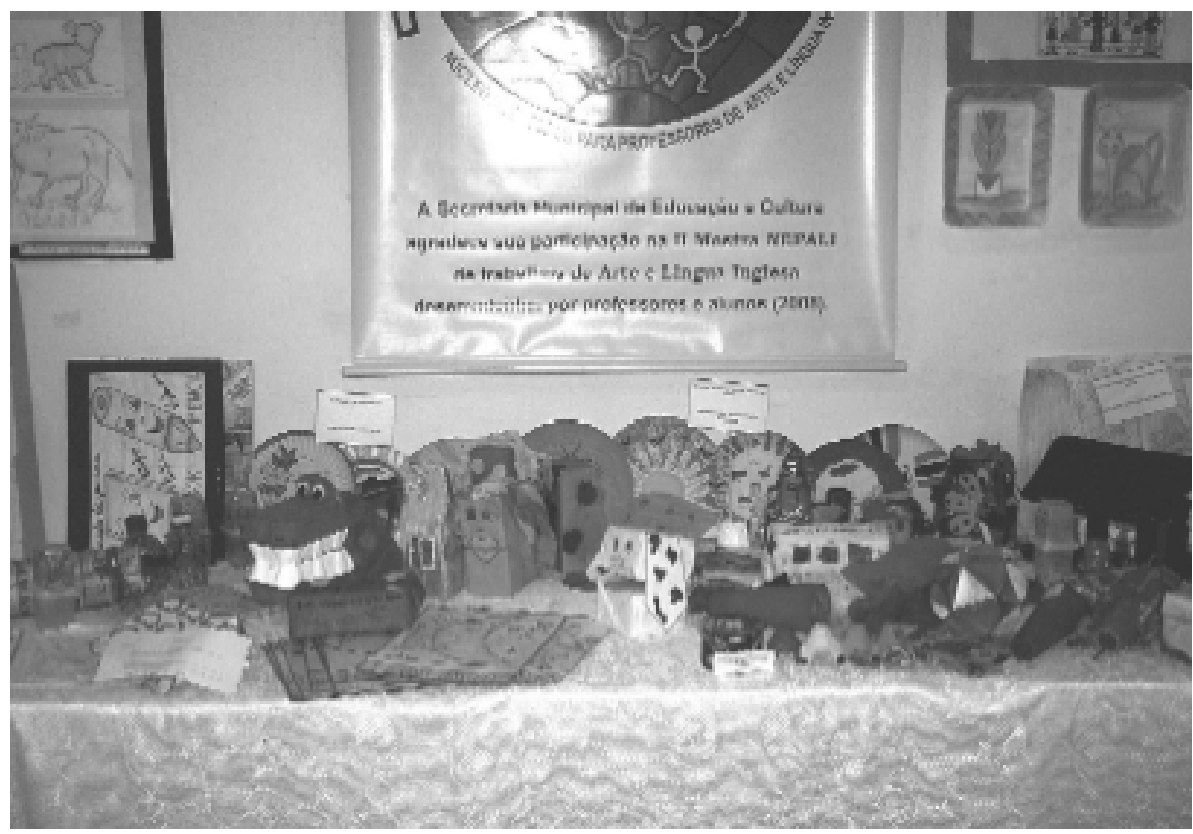

Figura 1 - Visão parcial do hall de entrada da UNEMAT na Mostra NEPALI
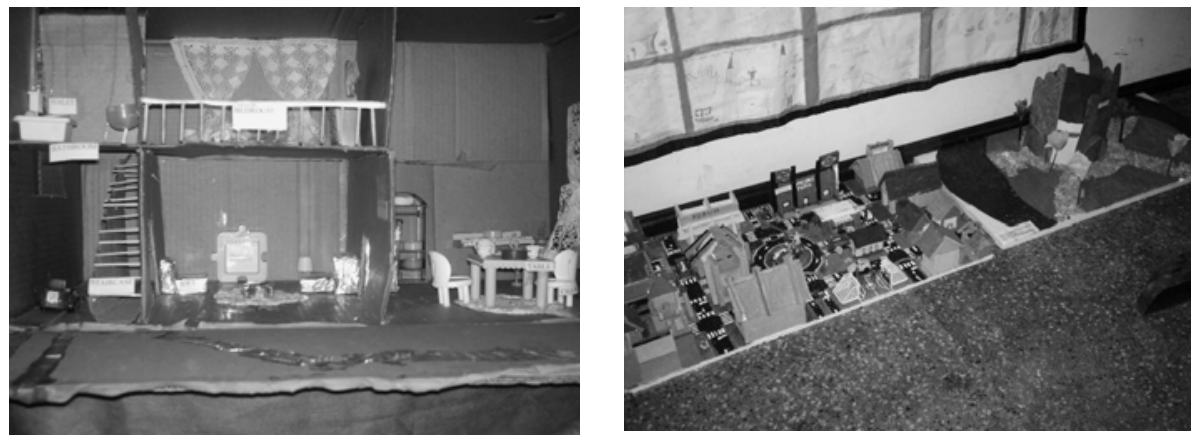

Figuras 2 e 3 - Maquetes desenvolvidas por alunos (partes da casa e lugares da cidade) 


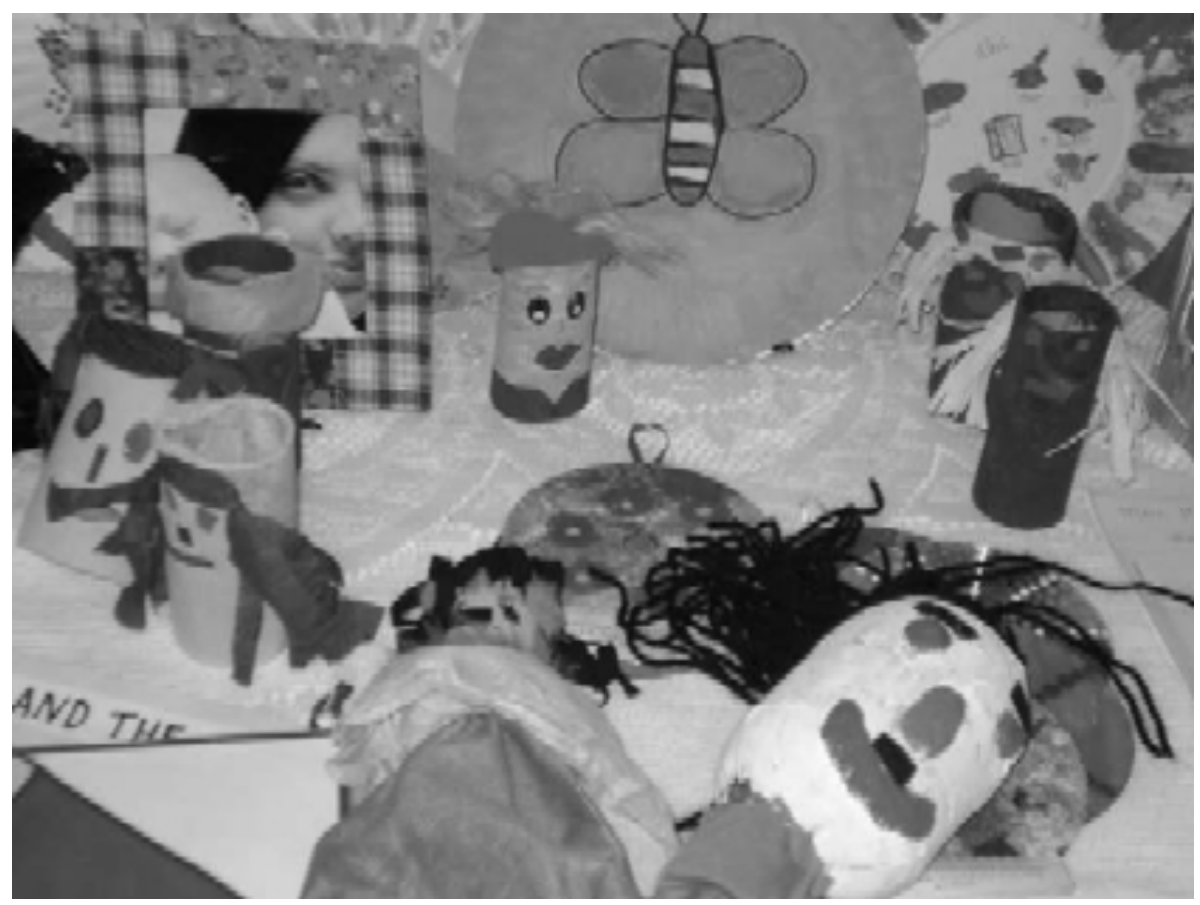

Figura 4 - Fantoches feitos com materiais reciclados (usados para apresentar conteúdos, dramatizações etc.)

Recebido em 11 de março de 2010. Aprovado em 18 de agosto de 2010. 